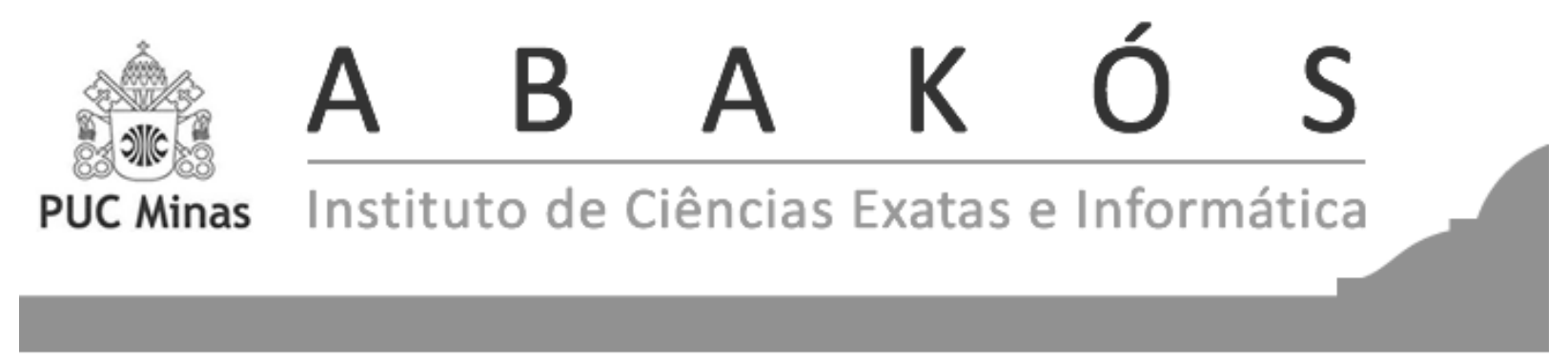

\title{
Objeto de Aprendizagem Virtual como Recurso Pedagógico Interativo para Resolução de Questões de Biologia no ENEM*
}

Virtual Learning Object as an Interactive Pedagogical Resource for Solving Biology Questions in ENEM

\author{
Marcus Vinícius Alves Nascimento ${ }^{1}$ \\ Cláudia de Vilhena Schayer Sabino
}

\begin{abstract}
Resumo
Entre as faculdades humanas destacam-se o conhecimento e o pensamento, talvez como as de maior importância. A escola se concentra em aumentar o conhecimento, e se esquece do pensamento. O Exame Nacional do Ensino Médio (ENEM) tem o firme propósito de avaliar a capacidade de pensar dos alunos, com foco no raciocínio e não mais no que o aluno decorou. O ENEM tem a maioria de suas questões direcionadas para mensurar a competência de resolver situações-problemas, construídas muitas vezes por meio de gráficos, que requerem interpretação para a tomada de decisões. Alunos da área de Biologia têm muitas vezes dificuldades para resolver problemas cuja solução depende da interpretação de gráficos. O presente trabalho apresenta um Objeto de Aprendizagem Virtual (OAV), um site, construído com base nos princípios da Teoria Cognitiva de Aprendizagem Multimídia (TCAM) e na técnica "Ação da roda", para resolução de problemas. Os resultados mostraram que a metodologia foi eficaz na aprendizagem, e que a técnica "Ação da roda", além de facilitar a resolução de problemas, pode contribuir para melhorar a habilidade de pensar e aprender.
\end{abstract}

Palavras-chave: ENEM. Análise de gráficos. Ação da roda. Aprendizagem multimídia. Objetos virtuais de aprendizagem.

\footnotetext{
*Submetido em 27/07/2018 - Aceito em 05/04/2019

${ }^{1}$ Mestre em Ensino de Ciências e Matemática, pela PUC Minas, Brasil- marcusbiologia@ gmail.com

${ }^{2}$ Doutora. Professora do Programa de Pós-graduação em Ensino de Ciências e Matemática da PUC Minas, Brasilsabinoc@pucminas.br
} 


\begin{abstract}
Among the human faculties, knowledge and thought are perhaps some of the most important. The school focuses on increasing knowledge, and forgets about thought. The National High School Examination (ENEM) has the firm purpose of evaluating students' thinking ability, with a focus on reasoning and no more on what the student has memorized. The ENEM has most of its questions directed at measuring the competence to solve problem situations, often constructed by means of graphs, that require interpretation for decision making. Students in the field of Biology often have difficulties in solving problems whose solution depends on the interpretation of graphs. The present work presents a Virtual Learning Object (OAV), a site, built on the principles of the Cognitive Theory of Multimedia Learning (TCAM) and the "Wheel Action" technique for problem solving. The results showed that the methodology was an effective tool in learning and that the "Wheel action" technique, besides facilitating problem solving, can contribute to improve the ability to think and learn.
\end{abstract}

Keywords: ENEM examination, Graphs analysis. Wheel action metodology. Multimedia learning. Learning objects. 


\section{INTRODUÇÃO}

Entre as faculdades humanas destacam-se o conhecimento e o pensamento, talvez como as de maior importância (AGGIO et al., 2016). A escola se concentra em aumentar o conhecimento, e se esquece do pensamento (ALMEIDA, 2010).

Ao analisar a situação atual do cenário brasileiro, não é difícil verificar a baixa qualidade da educação e a pouca eficiência do ensino em ajudar as pessoas a aprender e a pensar em níveis formais e abstratos (REBELATTO; TEDESCO, 2013). Não é necessária a formulação de descrições alongadas sobre evidências que corroboram esse cenário de má qualidade, bastando a constatação de resultados encontrados nas provas nacionais, tais como o SAEB (Sistema de Avaliação da Educação Básica) e o ENEM (Exame Nacional do Ensino Médio), entre outras. De fato, a qualidade das argumentações encontradas nas redações dos vestibulares, por exemplo, denuncia a dificuldade do aluno brasileiro em analisar, interpretar, relacionar, classificar, formar inferências plausíveis e expor argumentações coerentes.

Ensinar a pensar e propor um ensino que seja capaz de alterar o desenvolvimento do pensamento abstrato-formal dos estudantes é um desafio educacional brasileiro.

O ensino de ciências oferece múltiplas ocasiões para os alunos desenvolverem suas habilidades de pensar. A ciência desperta a curiosidade e o desejo de conhecer e de compreender (MAGOGA; MUENCHEN, 2018). Escolher os temas de pesquisa, inventar nomes para as novas espécies e construir modelos para representar fenômenos naturais são exemplos do papel da criatividade. Explorar os relatórios de uma pesquisa científica nas reivindicações sociais, evoluir os argumentos, interpretar as provas são alguns dos meios no ensino de ciências que podem encorajar os alunos ao pensamento.

O Exame Nacional do Ensino Médio (ENEM) desde sua criação mantém o firme propósito de avaliar a capacidade de pensar dos alunos (GUIMARÃES et al., 2006). Para isso cobra a interpretação de textos, gráficos, quadros e esquemas. Uma das grandes dificuldades dos alunos nas provas de biologia é enfrentar situações-problemas que envolvem a análise de gráficos. Sabem o assunto, mas têm dificuldades de interpretar "o que a questão pede", e isso se agrava quando os gráficos aparecem complementares à interpretação do problema (SILVEIRA et al., 2015). Resolver tais questões é:

[...] o enfrentamento de uma situação nova, exigindo pensamento reflexivo, crítico e criativo a partir dos dados expressos na descrição do problema; demanda a aplicação de princípios, leis que podem ou não ser expressas em fórmulas matemáticas. (ANASTASIOU et al., 2004, p. 86).

Este trabalho foi produzido com o objetivo de auxiliar os alunos a desenvolver a habilidade de pensar e consequentemente resolver problemas por meio do uso da técnica chamada "Ação da roda", proposta pelo professor canadense David Blades (1994). A "Ação da roda" é um método interativo constituído por uma série de etapas bem definidas que visam direcionar o aluno no enfrentamento de situações problemáticas, necessitando do uso do pensamento a 
partir de dados existentes no próprio problema. O trabalho é justificado pela necessidade de busca de um método concreto, capaz de auxiliar os estudantes em sua dificuldade de resolução de problemas, apoiado no desenvolvimento do raciocínio e não simplesmente na repetição de ações. Para isto foi desenvolvido, avaliado, otimizado e aplicado um objeto de aprendizagem virtual (OAV), no formato de um site ${ }^{3}$, com o objetivo de auxiliar na resolução de questões que envolvem gráficos no ensino de biologia. Constaram do OAV, criado com base nos princípios da Teoria Cognitiva de Aprendizagem Multimídia (TCAM), (MAYER, 1999) problemas do ENEM e/ou vestibulares dos últimos anos.

\section{REFERENCIAIS TEÓRICOS}

\subsection{O método ação da roda}

O ensino de ciências permite que os alunos desenvolvam suas habilidades de pensar através da curiosidade e da compreensão dos objetos de pesquisa. Segundo Blades (1994), o aluno usa sua criatividade construindo modelos, interpretando provas e elaborando relatórios de pesquisa. Fora do ambiente da sala de aula, o aluno dá importância à ciência e desenvolve o espírito crítico. No entanto, o estudante pode também desenvolver habilidades de pensamento em atividades pedagógicas alternativas, na própria sala de aula, como foi comprovado neste trabalho pela aplicação da técnica "Ação da Roda".

Blades (1994) criou um "Modelo interativo de resolução de problemas" conhecido como "Ação da Roda". A resolução de problemas na ciência envolve várias etapas, como um movimento dinâmico de várias ações. Para a resolução de um problema, deve-se entender a situaçãoproblema e formular ideias para tomar decisões na busca da solução. A Figura 1 apresenta o modelo e o Quadro 1 mostra as etapas da resolução de problemas que devem ser utilizadas durante a aplicação da técnica "Ação da Roda".

\footnotetext{
${ }_{3}^{3}$ Disponível em http://marcusbiologia.wixsite.com/marcusbiologia
} 
Figura 1 - Modelo interativo de resolução de problemas "Ação da roda"

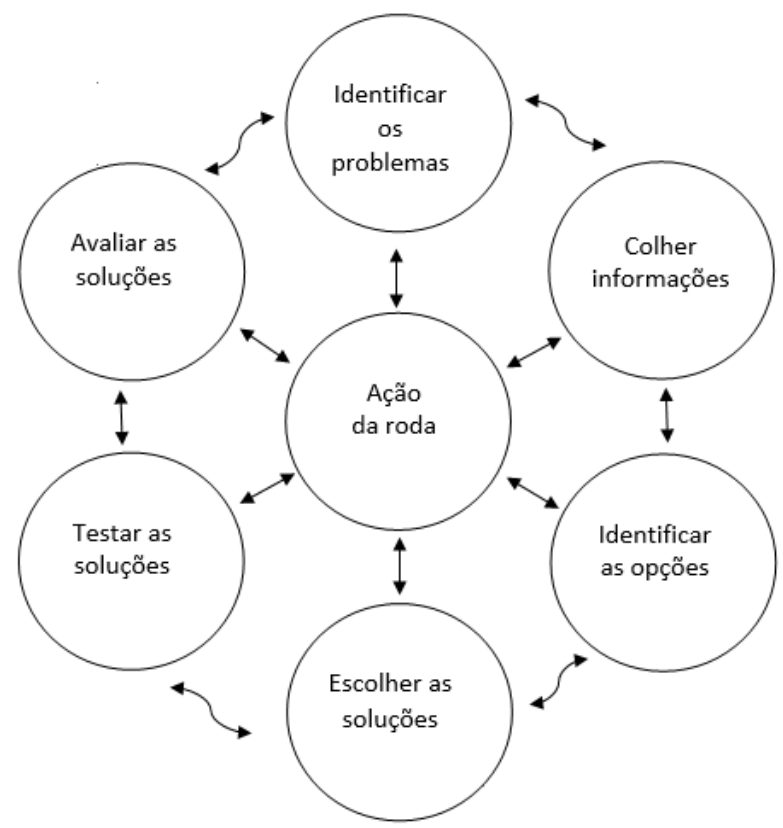

Fonte: Adaptado de Blades (1994).

Quadro 1 - Etapas do modelo "Ação da Roda” de resolução de problemas em Ciências Identificação do(s) problema(s)

Identificar o objetivo da investigação;

Distinguir entre os dados ou informações mais importantes;

Coletar e registrar informações gerais importantes;

Identificar todas as ideias, inclusive as implícitas;

Identificar os equipamentos adequados e materiais necessários;

Formular perguntas, hipóteses e/ou previsões que irão orientar a pesquisa;

Criar e/ou descrever um plano de pesquisa ou plano de resolução de problemas;

Elaborar gráficos ou diagramas necessários às observações.

\section{Coleta de informação}

Executar e modificar o processo, se necessário;

Organizar e utilizar adequadamente equipamentos e materiais;

Reunir informações ou dados tendo em conta as normas de segurança e fatores ambientais;

Observar e registrar com precisão os dados relevantes;

Organizar e apresentar dados de forma concisa e eficaz, podendo utilizar quadros, gráficos,

diagramas de Venn;

Comunicar os dados de forma mais eficiente utilizando os cálculos matemáticos;

Demonstrar um entendimento sobre o erro e, quando aplicável, calcular a porcentagem de erros.

Identificação das opções

Analisar dados e informações a fim de detectar tendências, padrões, relacionamentos,

confiabilidade e precisão;

Identificar e discutir fontes de erro e seu efeito sobre os resultados obtidos;

Analisar dados e informações, utilizando a tecnologia apropriada;

Identificar as características, as declarações, ou as razões pressupostas;

Identificar as principais ideias. 


\section{Escolha de soluções e Teste das soluções}

Fazer previsões a partir de dados ou informações;

Formular hipóteses testáveis a partir do conhecimento e da compreensão de acordo com o modo que foram elaboradas;

Identificar problemas ou outras questões;

Propor e explicar interpretações ou conclusões;

Desenvolver as explicações dos conceitos;

Resumir e expor os resultados;

Relacionar as leis, princípios, teorias ou modelos identificados com a informação em geral;

Responder ao problema em estudo;

Tomar uma decisão.

Avaliar as soluções

Considerar as consequências e seus desdobramentos;

Identificar as limitações dos dados e informações, interpretações ou conclusões, processos ou métodos utilizados para a experimentação, pesquisa, investigação, concepção do projeto; Sugerir alternativas e propor melhorias para a técnica ou desenho experimental;

Estabelecer os critérios para avaliar dados, ideias ou informações;

Avaliar as soluções alternativas.

Fonte: Adaptado de Blades (1994).

Nesse modelo o professor é o supervisor do aluno que deve desenvolver habilidades de pensamento crítico para a solução do problema. Essa técnica pode ser usada para a resolução de situações-problemas variadas, incluindo questões objetivas de Biologia contendo gráficos.

\subsection{Objeto de aprendizagem virtual (OAV) e Teoria Cognitiva de Aprendizagem Multimí- dia (TCAM)}

Tarouco et al. (2003) define objetos educacionais:

Objetos educacionais podem ser definidos como qualquer recurso, suplementar ao processo de aprendizagem, que pode ser reusado para apoiar a aprendizagem. O termo objeto educacional (learning object) geralmente aplica-se a materiais educacionais projetados e construídos em pequenos conjuntos com vistas a maximizar as situações de aprendizagem onde o recurso pode ser utilizado. (TAROUCO et al., 2003, p. 2).

Behar (2009) esclarece que os objetos de aprendizagem (OAs) se estendem a recursos como textos, animações, vídeos, imagens, aplicações, páginas da internet, de forma isolada ou combinados que visam auxiliar na aprendizagem dos alunos.

Segundo Audino e Nascimento (2010), apesar de inúmeras publicações e conceitos sobre os objetos de aprendizagem, não há um consenso referente à definição. Algumas conceituações são bastante amplas e define-os não apenas como instrumentos digitais e/ou virtuais. Ainda segundo os autores muito se deve ao fato de cada pesquisador definir os OAs de acordo com o que querem focar. 
Braga (2015) destaca a importância do professor, para além do modelo clássico de planejamento-preparação-condução do conteúdo: a ele cabe exercer o papel de agente ativo, responsável pela adequação pedagógica, no processo de produção de objetos de aprendizagem. $\mathrm{O}$ autor também ressalta a necessidade de o professor atual, muitas vezes necessitar de outros profissionais em equipe para obter melhorias no processo de ensino.

Percebe-se então a necessidade do surgimento de objetos de aprendizagem adequados à realidade de tempo e espaço dos sujeitos envolvidos na educação. Objetos que possibilitem aos envolvidos uma melhoria na qualidade da aprendizagem e no desenvolvimento de habilidades cognitivas.

A aprendizagem apoiada pelos recursos multimídia são objetos de estudo de Richard Mayer, Psicólogo, Pesquisador e Professor da Universidade da Califórnia. Em sua Teoria Cognitiva da Aprendizagem Multimídia (TCAM):

Uma hipótese fundamental dos estudos sobre aprendizagem multimídia é que as mensagens educacionais multimídia, concebidos a partir da forma como a mente humana funciona, têm mais probabilidades de levar a uma aprendizagem significativa do que as que não são. (MAYER, 2009, p. 207).

Para Mayer (2009), recursos multimídia devem ser construídos pela associação de imagens, sejam essas fixas ou em movimento, e com palavras, sejam escritas ou faladas. Segundo ele, as pessoas aprendem mais quando imagens e palavras estão juntas do que quando há apenas palavras. Os Princípios da Teoria Cognitiva da Aprendizagem Multimídia de Mayer estão apresentados na Quadro 2.

Quadro 2 - Princípios da Teoria Cognitiva da Aprendizagem Multimídia

\begin{tabular}{|l|l|}
\hline \multicolumn{1}{|c|}{ Princípio } & \multicolumn{1}{c|}{ Afirmação } \\
\hline $\begin{array}{l}\text { Proximidade } \\
\text { espacial }\end{array}$ & $\begin{array}{l}\text { Os alunos aprendem mais quando palavras e imagens correspondentes } \\
\text { estão mais próximas que afastadas (MORENO; MAYER, 1999). }\end{array}$ \\
\hline $\begin{array}{l}\text { Proximidade } \\
\text { temporal }\end{array}$ & $\begin{array}{l}\text { Os alunos aprendem mais quando palavras e imagens correspondentes } \\
\text { são apresentadas simultaneamente e não sucessivamente } \\
\text { (MORENO; MAYER, 1999). }\end{array}$ \\
\hline Personalização & $\begin{array}{l}\text { Os alunos aprendem melhor quando as palavras são escritas no estilo } \\
\text { da conversação ao invés do estilo formal. (MAYER apud SORDEN, 2012, } \\
\text { p.8) }\end{array}$ \\
\hline Coerência & $\begin{array}{l}\text { Os alunos aprendem mais quando imagens, sons e palavras não relevantes } \\
\text { ao tema são excluídas (MAYER apud SORDEN, 2012, p.8) }\end{array}$ \\
\hline
\end{tabular}

Fonte: Adaptado de Moreno e Mayer (1999).

\section{METODOLOGIA}

A metodologia foi pesquisa-ação, que de acordo com Pimenta (2005) tem como um dos pressupostos, os indivíduos envolvidos comporem um grupo com objetivos e metas em comum, 
por isso a ação, o agir está vinculado ao modo de ser, e é possível identificar o que se é no que se faz, pois, as ações são práticas e constituem-se a partir da história de cada sujeito.

O trabalho foi realizado em duas etapas, conforme apresentado na Figura 2. A primeira etapa envolveu o desenvolvimento, avaliação e otimização do site, enquanto que a segunda etapa consistiu em sua aplicação como ferramenta de ensino aprendizagem.

Figura 2 - Etapas metodológicas da pesquisa

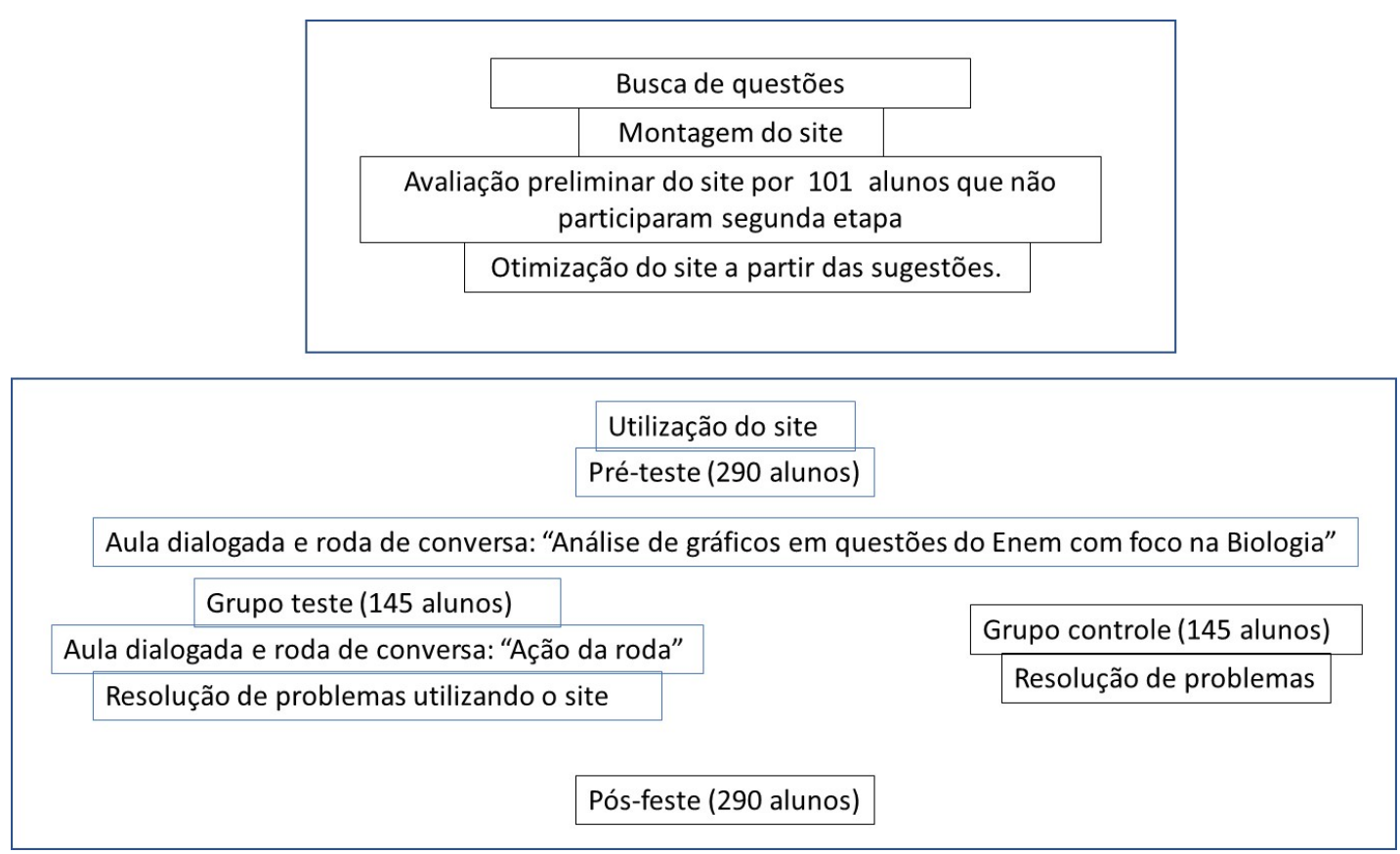

Fonte: Os autores.

\subsection{Primeira etapa}

\subsubsection{Busca de questões}

A primeira atividade foi a seleção das questões que seriam apresentadas no site. Por meio de pesquisa na página do Instituto Nacional de Estudos e Pesquisas Educacionais Anísio Teixeira (INEP, 2018) foi possível coletar as questões em arquivos digitais de todas as versões do ENEM. A maioria das selecionadas, continha gráficos de barras, principalmente barras verticais e gráficos de linhas. O banco de questões foi ampliado com outros problemas oriundos de provas de vestibulares de diferentes universidades brasileiras.

\subsubsection{Montagem do site}

Foram construídas páginas virtuais contendo informações e imagens sobre os diferentes tipos de gráficos usando os Princípios Multimídia e da Coerência da Teoria Cognitiva da Abordagem Multimídia Mayer (1999). O passo seguinte foi vincular as páginas de diferentes tipos 
de gráficos com questões, preferencialmente do ENEM, que contivessem o tipo pesquisado. Todas as questões foram identificadas com a fonte e o ano de sua aplicação.

Uma página sobre o modelo de resolução de problemas "Ação da roda" foi incluída para a descrição, explicação de sua origem e exemplificação da aplicação na resolução de questões objetivas. Todas as questões incluídas no site foram resolvidas usando a sequência de etapas da "Ação da roda", para mostrar como essa técnica pode ensinar a pensar e consequentemente conduzir à solução de um problema.

Para concluir a construção do site, na página inicial foi colocado um texto introdutório com informações sobre o objetivo do mesmo, a importância dos gráficos no cotidiano e a ocorrência de questões envolvendo a análise de gráficos nas provas do ENEM.

\subsubsection{Avaliação preliminar do site}

Participaram da avaliação 101 alunos de Cursos preparatórios para o ENEM. Esses alunos não participaram da segunda etapa, ou seja, da aplicação do site.

De acordo com Carvalho et al. (2005) ainda não há nenhuma norma internacional para a avaliação de site, mas existem alguns indicadores que podem auxiliar na avaliação de qualidade. Critérios como a facilidade de uso, a qualidade das informações, a autoria, além de outros foram seguidos em conformidade com Carvalho et al. (2005) para a construção e avaliação do OAV.

Mediante tais critérios da avaliação da qualidade foi construído um questionário virtual de opinião para que alunos pudessem avaliar o OAV após visita e utilização. Foi estipulado o período de um mês para o trabalho. Cerca de 300 alunos de cursos preparatórios das cidades de Belo Horizonte e Sete Lagoas foram convidados a participar da pesquisa por meio do formulário existente no próprio site. Desse total, 101 preencheram o formulário.

O questionário foi constituído de 13 perguntas obrigatórias, sendo 11 de múltipla-escolha e 2 discursivas, elaboradas visando verificar se o site se encaixava em diferentes indicadores de qualidade, e se contribuía para o aprendizado de acordo com os critérios da TCAM. Após o período determinado foi feita uma tabulação e análise dos resultados.

\subsubsection{Otimização do site}

Algumas críticas e/ou sugestões, feitas pelos alunos no questionário de avaliação, foram atendidas. 


\subsection{Segunda etapa}

\subsubsection{Sujeitos da pesquisa}

Participaram da pesquisa dez turmas de Ensino Médio de uma Rede de Ensino de Belo Horizonte, totalizando 290 alunos. Para todos foi feita a divulgação do trabalho, sem, contudo, citar a existência do site nem o uso da técnica "Ação da Roda". Foi abordada a necessidade de saber resolver questões de biologia do ENEM contendo gráficos.

Os alunos foram divididos em dois grupos, metade formou o grupo teste (com intervenção), que trabalhou com a técnica "Ação da roda" em sala de aula e o uso do site. A outra metade formou o grupo-controle (Figura 2).

\subsubsection{Elaboração dos testes}

Uma pesquisa foi feita nos sites de universidades públicas e privadas brasileiras que ainda usam vestibulares como forma de seleção para encontrar questões objetivas para a construção dos testes de pré e pós-intervenção. Questões de vestibulares oriundas da FUVEST, UEL, Unicamp, UERJ, Vunesp, PUC Minas, PUC-Rio e PUC-SP foram pesquisadas e selecionadas. Foram escolhidas as que se encaixavam em dois critérios: o primeiro é que elas deveriam conter gráficos com uma situação-problema, e o segundo é que deveriam ser questões cujo índice de acerto (nível de dificuldade) fosse conhecido. Informações sobre o índice de acerto de cada questão podem ser encontradas, geralmente, na parte de estatísticas do vestibular disponibilizadas no site das próprias Instituições.

Apenas questões com índice de acerto entre 40 e $65 \%$ foram escolhidas por serem consideradas medianas pelas instituições. Após essa seleção, cinco questões foram escolhidas para compor o pré-teste e cinco para o pós-teste, como o objetivo de garantir que ambos tivessem grau de dificuldade parecido.

Uma vez que os testes foram construídos a partir de questões possíveis de serem encontradas na internet incluindo respostas e às vezes comentários, os testes foram reproduzidos em papel e aplicados. O objetivo desse procedimento foi garantir a participação real do aluno baseada em seu conhecimento, pois em um teste virtual o estudante poderia simplesmente consultar o gabarito online e marcar a resposta correta.

Após a aplicação, as questões foram corrigidas conforme gabarito oficial das instituições nas quais foram obtidas, e os resultados de cada aluno por turma foram tabulados por questão.

Ao final do pós-teste os estudantes do grupo de controle foram informados sobre a existência do site contendo informações adicionais que poderiam servir como ferramenta de aprendizagem. Foi solicitado que após visita e navegação pelo site, eles avaliassem o modelo de resolução de questões. O próprio site tem uma ferramenta que permite o envio de mensagens 
para o administrador.

\subsubsection{Aula dialogada e roda de conversa}

A aula dialogada teve a duração de uma hora-aula e foi dividida em dois momentos: na primeira parte foi realizada a apresentação do conteúdo e, na segunda, uma roda de conversa, que envolveu discussão e resolução de questões objetivas. Com o objetivo de facilitar a análise de dados qualitativos, foi solicitado que o "representante de turma" anotasse os comentários e perguntas referentes aos assuntos abordados durante as atividades.

\subsubsection{Intervenção}

Após uma semana, o grupo teste participou de uma aula dialogada e roda de conversa, sobre o modelo: ação da roda na resolução de questões do ENEM. Essa, novamente consistiu em apresentação de conteúdo, seguida de roda de conversa que incluiu a resolução de questões objetivas. Nessa mesma aula foram apresentadas outras aplicações da técnica na resolução de situações-problemáticas, e o site foi amplamente divulgado, com a justificativa que auxiliaria ainda mais os alunos no domínio da técnica. O aluno "representante de turma" foi novamente solicitado para anotar os comentários e perguntas.

Por três semanas, com o auxílio de professores, também de outras disciplinas, os alunos foram estimulados frequentemente a navegarem pelo site. Lá, conheceriam mais sobre a aplicação da técnica e poderiam enviar comentários e avaliações sobre a técnica e sobre o site. Após esse prazo os alunos do grupo teste foram informados que fariam um pós-teste.

\subsubsection{Análise dos dados}

O último passo do trabalho foi feito por meio da análise e comparação dos resultados quantitativos e qualitativos. A análise qualitativa foi realizada por meio da análise dos comentários dos alunos nas aulas, bem como os recebidos por meio da ferramenta existente no site. 


\section{RESULTADOS E DISCUSSÕES}

\subsection{Primeira etapa}

\subsubsection{Montagem do site}

O site construído está disponível em: https://marcusbiologia.wixsite.com/marcusbiologia.

Por meio de pesquisa no site do INEP, foi encontrada uma considerável ocorrência de questões envolvendo a análise de gráficos. Nas provas do ENEM de 1998 a 2008: 14\% das questões continham gráficos. A pesquisa envolveu também minuciosa análise das provas de Ciências da Natureza de todos os exames de 2009 a 2015, e os resultados referentes à ocorrência de questões contendo gráficos nessa área foram entre 5 e 22\%, nas diversas aplicações. A partir de 2009, o ENEM passou a ser usado como acesso às Instituições Federais de Ensino Superior, o que ocasionou algumas modificações nas provas.

Inicialmente foram construídas as páginas que continham informações sobre os diferentes tipos de gráficos, totalizando oito páginas: gráficos de barras verticais, horizontais, acumuladas e agrupadas assim como gráficos de setores, de linhas, histogramas e pictograma. Um exemplo é apresentado na Figura 3.

Todas as páginas com descrição do tipo de gráfico são acompanhadas de um exemplo retirado de questões de versões anteriores de provas do ENEM. Um clique sobre a imagem direciona para a página com a interpretação do referido gráfico e resolução do problema utilizando a técnica Ação da roda. Um exemplo é apresentado no Apêndice deste trabalho.

À medida que o produto foi sendo construído foi possível observar uma multidisciplinaridade, o que auxilia o estudante a pensar, assim como enfrentar situações-problemas de diferentes áreas por meio da resolução de questões.

Dentre as questões selecionadas nas diferentes versões do ENEM, foram escolhidas três, para exemplos de cada um dos oito tipos de gráficos abordados. Apenas questões que continham assuntos relacionados aos conteúdos de Biologia foram usadas e, em alguns casos, houve a necessidade do uso complementar de questões de vestibulares tradicionais. Em todas foram citadas a fonte da questão, o ano de aplicação e o número original na prova. Para cada uma das 24 questões, o passo a passo da técnica "Ação da roda" foi apresentado para mostrar os caminhos a serem seguidos na resolução de um problema, auxiliando o aluno a aprender a pensar.

\subsubsection{Resultados da avaliação preliminar do site}

Após a conclusão do site, uma pesquisa de opinião sobre a qualidade deste foi feita com 101 alunos de cursos livres preparatórios para o ENEM das cidades de Belo Horizonte e Sete 
Figura 3 - Exemplo de página informativa sobre tipo de gráfico

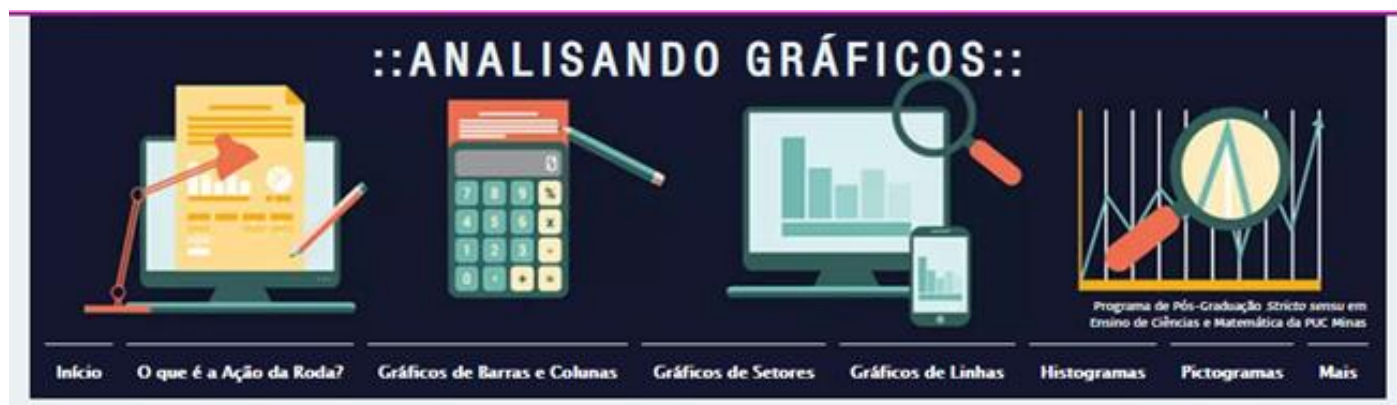

\section{Gráficos de Barras Agrupadas}

São utilizados para mostrar os valores dos componentes para o total de uma categoria. As barras podem ser: verticais ou horizontais. Apresenta legenda para identificação dos componentes da categoria.

Observe o exemplo abaixo e clique no gráfico para obter informações.

Tipos sanguineos

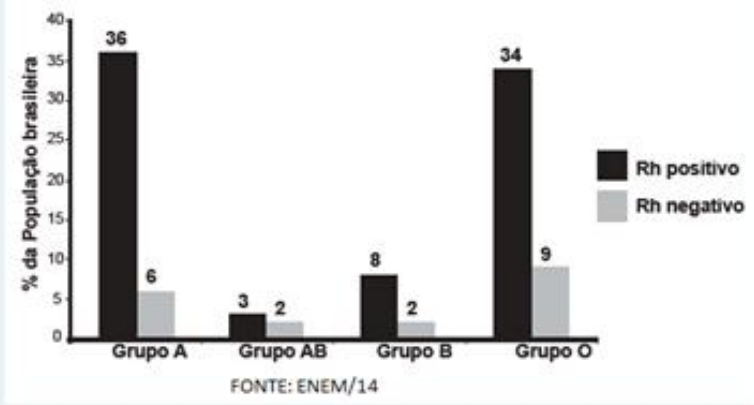

Fonte: https://marcusbiologia.wixsite.com/marcusbiologia/barras-agrupadas.

Lagoas. Os resultados da pesquisa estão apresentados a seguir.

$1^{a}$ pergunta: “O site é fácil de usar?” 95,0\% responderam sim e 5,0\% não. A facilidade do uso, constatada pelos respondentes, pode ser explicada pelo fato de sua construção ter levado em conta princípios da Aprendizagem Multimídia (MAYER, 1999). Os dois princípios mais usados foram o "Multimídia" e o "da Coerência", de acordo com o primeiro a aprendizagem é melhor quando as multimídias são construídas usando palavras e imagens e, de acordo com o segundo, a aprendizagem é melhor quando palavras e imagens não relevantes ao assunto são excluídas.

$2^{\text {a }}$ pergunta: "As informações presentes no site são claras contribuindo para o aprendizado?" 96,0\% responderam sim e 4,0\% não. Tais informações seguiram o Princípio da Personalização (MAYER, 1999) que propõe que os alunos aprendem mais quando as palavras estão no estilo de conversação.

$3^{\text {a }}$ pergunta: "A autoria da informação é de confiança?" 100,0\% responderam sim. A justificativa para o resultado da pesquisa pode ser explicada pela confiança construída na sala de aula, com a relação de docência previamente estabelecida entre o professor e os "entrevistados" assim como o respaldo e a credibilidade da instituição à qual esta pesquisa está vinculada, isto é, a PUC Minas. Além disso, o uso de questões do ENEM e de vestibulares de importantes 
e renomadas universidades reforçou a confiança dos alunos. Segundo Carvalho et al. (2005), "a autoria de um site refere-se tanto ao autor da informação visualizada como à instituição ou pessoa responsável pelo site ou pela informação."

$4^{a}$ pergunta: “As páginas demoram em carregar?" 95,0\% responderam não e 5,0\% sim. Segundo Nielsen (2000), uma página não deve demorar mais de dez segundos para carregar. Como apenas uma pequena parcela das avaliações apontou problemas no carregamento das páginas é provável que isso se deva à velocidade das conexões usadas. Alguns alunos não conseguiram acessar o site usando o telefone celular. Essa constatação motivou o desenvolvimento de uma versão adaptada para a visualização em celulares, que já está disponível.

5 a pergunta: "O conteúdo do texto é adequado ao título das páginas?" 100,0\% responderam sim. O resultado pode ser justificado pelo fato de que o conteúdo de cada página (texto e gráfico) é apenas aquele informado no título, seguindo o Princípio de Contiguidade Espacial (MAYER, 2001).

$6^{\text {a }}$ pergunta: "Os links localizados no alto do site estão adequados?” 98,0\% responderam sim e 2,0\% não. Como o assunto abordado no trabalho é análise e interpretação de grácos, e esses estão no site de forma direta e objetiva, links com assuntos não relacionados foram abolidos, seguindo o Princípio da Coerência (MAYER, 2001) e garantindo o resultado alcançado.

7 a pergunta: "As opções "VOLTAR" estão adequadas?" 91,1\% responderam sim e 8,9\% não. Os respondentes que possivelmente usaram conexões rápidas (Questão 4) declararam ser a opção eficiente. A ineficiência na opção "VOLTAR" talvez possa ser atribuída à má qualidade da conexão individual.

$8^{a}$ pergunta: "A cor do texto é agradável para leitura?" $83,2 \%$ responderam sim e 16,8\% não. A cor foi o item de pior avaliação, por isso foi alterada. Segundo Nielsen (2000), a cor do texto deve ser contrastante com a do fundo, preferencialmente texto escuro sobre fundo claro.

9 $9^{a}$ pergunta: “O alinhamento dos textos está adequado?" 91,1\% responderam sim e $8,9 \%$ não. Todas as páginas do site têm o texto justificado e os problemas no alinhamento apareceram quando a visualização foi feita via uso de celular, antes do desenvolvimento do formato apropriado.

$10^{a}$ pergunta: “As figuras são claras e fáceis de serem visualizadas?” 93,1\% responderam sim e 6,9\% não. Na confecção do site foram usadas apenas imagens de gráfico com alto grau de resolução, e os problemas na visualização ocorreram quando a visita ao site era feita por meio do uso de celular.

$11^{\text {a }}$ pergunta: "O tamanho da fonte (das letras) está adequado?" 95,0\% responderam sim e 5,0\% não. Esse foi um item bem avaliado e por isso não houve alteração.

$12^{a}$ pergunta: “O que pode ser melhorado no site?” As respostas estão apresentadas na Quadro 3.

Uma das respostas que mais apareceu foi a necessidade da melhoria do layout geral e cores do site, questão essa que foi levada em consideração para que a visão geral fosse melhorada. Outra solicitação foi o acréscimo de mais questões, bem como de vídeos explicativos, infográficos e outros temas. Essas solicitações/demandas não foram atendidas, pois não é a proposta 
Quadro 3 - Respostas para a pergunta: “O que pode ser melhorado no site?”

\begin{tabular}{|c|c|}
\hline Resposta & \% de respostas \\
\hline Nada & 27 \\
\hline Melhorar a estética/formatação/estrutura e layout geral & 23 \\
\hline Acrescentar mais exemplos/mais questões & 14 \\
\hline Melhorar as cores & 11 \\
\hline Acrescentar vídeos explicativos, infográficos e outros temas & 9 \\
\hline Versão móbile & 5 \\
\hline Melhorar as explicações em geral e da técnica “Ação da roda” & 3 \\
\hline Melhorar ortografia/acentuação/compreensão do texto & 3 \\
\hline Outros & 3 \\
\hline Colocar a possibilidade "faça você mesmo" & 2 \\
\hline
\end{tabular}

Fonte: Resultado da pesquisa.

deste produto ser um banco de questões, ou abordar outros temas, e sim usar a técnica "Ação da roda" na resolução de questões objetivas. Ainda cabe salientar que a plataforma gratuita na qual o site foi construído (WIX), não permite a inserção de vídeos. O pedido de versão mobile foi atendido.

$13^{\text {a }}$ pergunta: “O que mais chamou a atenção no site? Isso é bom ou ruim?". As respostas estão apresentadas no Quadro 4. 100,0\% dos alunos mencionaram aspectos considerados bons.

\section{Quadro 4 - Respostas da pergunta: “O que mais chamou a atenção no site? Isso é bom ou ruim?"}

\begin{tabular}{|l|c|}
\hline \multicolumn{1}{|c|}{ Resposta } & \% de respostas \\
\hline O uso da técnica: “Ação da Roda” & 23 \\
\hline As informações e explicações sobre os tipos de gráficos & 23 \\
\hline Organização geral do site & 19 \\
\hline Facilidade de uso & 15 \\
\hline Uso de gráficos e sua relação com a biologia & 8 \\
\hline Uso de questões de ENEM e vestibulares & 6 \\
\hline Outros & 6 \\
\hline
\end{tabular}

Fonte: Resultado da pesquisa.

O resultado da avaliação foi bastante positivo, provavelmente pela elaboração dentro dos princípios da Aprendizagem Multimídia (MAYER, 1999) e do uso da técnica "Ação da roda" (BLADES, 1994). Os princípios da TCAM garantiram a qualidade nas informações e explicações, bem como com uma boa organização geral facilitando o aprendizado, de acordo com a opinião dos respondentes. A técnica "Ação da roda" também agradou aos entrevistados uma vez que fornece uma possibilidade a mais para resolver questões objetivas, com grande chance de se chegar à resposta correta a partir do passo a passo. 


\subsection{Segunda etapa}

\subsubsection{Resultados do pré e pós-teste}

Tendo em vista que o número de alunos em cada grupo foi grande $(>100)$ e que apenas uma variável foi considerada, (nota no teste) os cálculos estatísticos foram feitos considerando distribuição normal, de acordo com a Lei dos Grandes Números. O Quadro 5 apresenta alguns parâmetros relacionados às notas dos testes.

Quadro 5 - Parâmetros relacionados às notas dos testes

\begin{tabular}{|l|c|c|c||c|c|c|}
\hline & \multicolumn{3}{|c|}{ Pré teste } & \multicolumn{3}{c|}{ Pós teste } \\
\hline & $\mathbf{N}$ & Média & Desvio padrão & N & Média & Desvio padrão \\
\hline Com intervenção & 105 & 3.06 & 0.98 & 133 & 3.63 & 0.95 \\
\hline Sem intervenção & 118 & 3.15 & 1.08 & 124 & 3.10 & 0.99 \\
\hline
\end{tabular}

Fonte: Dados da pesquisa.

Foi aplicado o teste-t, às duas amostras presumindo variâncias equivalentes para as notas do pré-teste. Foi observado que as notas da turma com intervenção foram iguais às da turma sem intervenção $(\mathrm{p}=0,58)$, o que sugere que o conhecimento sobre questões com gráficos era o mesmo antes do início do experimento.

O teste-t, também foi aplicado às duas amostras presumindo variâncias equivalentes para as notas do pós-teste. Foi observado que as notas da turma com intervenção foram diferentes da turma sem intervenção $(\mathrm{p}=0,00)$, o que sugere que o conhecimento sobre questões com gráficos foi diferente ao final do experimento, ou seja, a turma que aprendeu a técnica "Ação da roda"e usou o site apresentou melhor resultado.

\subsubsection{Aula dialogada e roda de conversa inicial}

Todos os alunos participaram da aula dialogada e roda de conversa inicial. Os alunos foram orientados a aplicar um pouco mais dos conhecimentos de outras disciplinas, em questões de Biologia. Foram feitas várias intervenções durante a aula. O Quadro 6 apresenta alguns dos comentários mais frequentes, anotados pelos representantes de turma, durante a aula. 
Quadro 6 - Comentários dos alunos durante a aula "Análise de gráficos no ENEM"

\begin{tabular}{|l|l|}
\hline Aluno 1 & $\begin{array}{l}\text { "Questões de gráficos são comuns em Matemática e raramente têm relação com } \\
\text { Biologia." }\end{array}$ \\
\hline Aluno 2 & "Pode até “cair" no ENEM alguma questão com gráfico, mas é pouco comum." \\
\hline Aluno 3 & $\begin{array}{l}\text { "Se aparecer alguma questão com gráfico tenho que saber basicamente } \\
\text { princípios da Matemática." }\end{array}$ \\
\hline Aluno 4 & "Esses tipos de gráficos já foram estudados na Matemática." \\
\hline Aluno 5 & $\begin{array}{l}\text { "Bom ter essa aula, pois nunca nenhum professor de Biologia ensinou gráfico } \\
\text { pra nós, só o professor de Matemática." }\end{array}$ \\
\hline Aluno 6 & $\begin{array}{l}\text { "O mais difícil dessa questão não é o conteúdo de Biologia e sim saber ler o } \\
\text { gráfico." }\end{array}$ \\
\hline Aluno 7 & "Questões que contém esse tipo de análise só dificulta nossa vida." \\
\hline Aluno 8 & "A presença do gráfico em uma questão vai me fazer errá-la." \\
\hline Aluno 9 & $\begin{array}{l}\text { "Questões que envolvem gráfico são mais fáceis já que basta saber interpretar } \\
\text { sem necessidade de saber do conteúdo." }\end{array}$ \\
\hline Aluno 10 & "Apareceu um gráfico ou um quadro numa questão já complica as coisas" \\
\hline
\end{tabular}

Fonte: Dados da pesquisa.

Salienta-se que durante essa aula os alunos tiveram contato com algumas das questões do site, mas sem o uso da técnica "Ação da roda", de forma que discutiram as questões com base em conhecimentos prévios acumulados, principalmente, das aulas de Matemática.

\section{Aula de resolução de questões com a técnica "Ação da roda":}

Essa aula foi ministrada apenas para o grupo teste. Inicialmente, os alunos tiveram muitas dúvidas sobre o uso da técnica, mas gradativamente foram aprendendo-a, aplicando-a e fizeram ponderações diversas. Durante a aula foi divulgada a existência do site. O Quadro 7 apresenta observações dos alunos durante a aula. 


\section{Quadro 7 - Comentários dos alunos durante a aula "Ação da roda na resolução de questões do ENEM"}

\begin{tabular}{|l|l|}
\hline Aluno 1 & "Eu já uso uma técnica de raciocínio parecida com essa na resolução de questões." \\
\hline Aluno 2 & "Essa técnica pode ser usada para resolver outro tipo de questão?" \\
\hline Aluno 3 & $\begin{array}{l}\text { "É uma técnica que demanda tempo para aprender e caso eu não consiga, posso } \\
\text { me confundir com ela." }\end{array}$ \\
\hline Aluno 4 & $\begin{array}{l}\text { "É bem mastigada a forma de resolver problemas usando essa técnica. Não tem } \\
\text { como errar." }\end{array}$ \\
\hline Aluno 5 & "Gostei dela, pois se parece com minha forma de pensar e organizar as ideias." \\
\hline Aluno 6 & $\begin{array}{l}\text { "Usando um raciocínio assim fica fácil de encontrar a solução de qualquer } \\
\text { problema." }\end{array}$ \\
\hline Aluno 7 & $\begin{array}{l}\text { "Pode ser gráfico, quadro, problema ou texto. Com um passo a passo desse fica } \\
\text { mais fácil aprender." }\end{array}$ \\
\hline Aluno 8 & $\begin{array}{l}\text { "Acho que isso deveria ser ensinado para crianças para que elas desde cedo } \\
\text { aprendam a pensar." }\end{array}$ \\
\hline Aluno 9 & $\begin{array}{l}\text { "É uma forma bem detalhada de resolver uma questão, mas com a prática ajuda a } \\
\text { desenvolver a rapidez do raciocínio." }\end{array}$ \\
\hline Aluno 10 & "Gostei dela por cercar o problema de todas as formas." \\
\hline
\end{tabular}

Fonte: Dados da pesquisa.

\subsubsection{Comentários dos alunos sobre o site}

Os alunos responderam o questionário online e comentaram temas abordados nas atividades. O Quadro 8 contém alguns dos comentários.

\section{Quadro 8 - Comentários de alunos que visitaram o site}

"Gostei bastante da técnica para nos ajudar a pensar nas questões, mas acho que ela deveria ser ensinada não no final do ensino médio e sim ao longo de toda a educação básica para ajudar os alunos a pensar melhor."

"Pra mim o método é válido, só acho que ao realizar a escolha da solução já meio que é feito um teste nela, tipo um "combo", então pra mim seria um passo só. Mas achei ótima e extremamente aplicável!"

"Vale a pena investir nesse projeto. Tem uma linguagem simples e fácil de entender sendo que ajuda na aplicação do método de compreender os gráficos."

"O site está muito bem construído, além de ser fácil de achar o que quer. Os gráficos são bons para treinar análise e ajuda em provas."

"Gostei muito do site, várias dicas boas e úteis!"

"O site está muito bem estruturado, com um conteúdo de boa qualidade e bastante prático."

"Muito boa a técnica sugerida ajudou bastante na hora do ENEM."

"Gostei muito da maneira como esse site nos permite raciocinar e chegar a uma resposta de maneira autônoma. Bom trabalho!!"

"Site muito bom e explicações super esclarecedoras!"

"Show de bola!!"

\section{Fonte: Dados da pesquisa.}

É possível observar, por meio da leitura e interpretação dos comentários, que os alunos ficaram satisfeitos com a organização geral do site, e que a técnica "Ação da roda" mostrou ser uma ferramenta aplicável para ajudá-los a resolver questões e a desenvolver o raciocínio. 


\section{CONCLUSÕES}

As provas do ENEM são constituídas de questões contextualizadas e multidisciplinares elaboradas visando mensurar o raciocínio dos alunos. São questões com foco central na resolução de problemas que, por sua vez, demandam muito mais que uma simples memorização, a capacidade de estabelecer conexões. Para isso há a necessidade de mudança nos métodos de ensino e aprendizagem que não devem mais ser baseados em memorização e repetição.

Diante dessa necessidade são necessárias ferramentas e metodologias que ampliem a possibilidade de ensinar o aluno a aprender e a pensar, o que levou à construção de um objeto de aprendizagem virtual, um site, denominado "Analisando Gráficos", que incluiu a técnica "Ação da roda" como metodologia capaz de ajudar os discentes a alcançar esse objetivo.

O site construído com bases em princípios da TCAM e alterado conforme pesquisa entre "clientes", foi a ferramenta essencial para atingirmos alunos em espacialidade e temporalidade diferentes, o que é uma das vantagens da educação a distância. Por meio do site, a técnica "Ação da roda" foi difundida para auxiliar na resolução de questões que envolviam a análise de gráficos, assim como contribuiu para o desenvolvimento da habilidade de pensamento.

De um grupo de mais que 200 alunos, sujeitos dessa pesquisa, cerca da metade usou o site como ferramenta e a técnica como metodologia e, em virtude disso, apresentou um desempenho quantitativamente superior quando comparado com o grupo que não a usou.

O site foi considerado pelos alunos, uma ferramenta simples, bem estruturada, de qualidade e de fácil acesso. Assim como a técnica foi considerada uma boa estratégia de desenvolvimento de raciocínio, uma vez que possibilitou o enfrentamento de situações-problemas por meio de uma sequência de passos que contribuem no desenvolvimento da habilidade de pensamento do aluno.

Este trabalho apresentou uma ferramenta e uma técnica na resolução de questões de Biologia envolvendo a análise de gráficos, que se mostram também eficazes na contribuição de desenvolvimento de habilidades e resolução de problemas em outras áreas do conhecimento.

$\mathrm{O}$ uso das metodologias alternativas descritas facilitou o processo ensino/aprendizagem. 


\section{REFERÊNCIAS}

AGGIO, Natalia Maria; POSTALLI, Lidia Maria Marson; GARCIA, Lucas Tadeu. Implicações educacionais da concepção comportamental de pensamento: ensinar a pensar e a resolver problemas. Perspectivas em análise do comportamento, v. 7, n. 1, p. 48-58, 2016.

ALMEIDA, Vanessa Sievers de. A distinção entre conhecer e pensar em Hannah Arendt e sua relevância para a educação. Educação e Pesquisa, SciELO Brasil, v. 36, n. 3, 2010.

ANASTASIOU, Léa das Graças Camargos; ALVES, Leonir Pessate et al. Estratégias de ensinagem. In: ALVES, Leonir Pessate; ANASTASIOU, Léa das Graças Camargos. Processos de Ensinagem na Universidade: Pressupostos para as estratégias de trabalho em aula. Joinville: Univille, 2004. v. 3, p. 67-100.

AUDINO, Daniel Fagundes; NASCIMENTO, Rosemy da Silva. Objetos de aprendizagemdiálogos entre conceitos e uma nova proposição aplicada ã educação. Revista Contemporânea de Educação, v. 5, n. 10, 2010.

BEHAR, Patricia Alejandra. Modelos pedagógicos em educação a distância. [S.1.]: Artmed Editora, 2009.

BLADES, David. Enseigner à penser. In: ALBERTA DEPT. OF EDUCATION. Sciences secundarie deuxieme cicle: Guide d'eisengnement. Canadá: [s.n.], 1994. Capítulo 3A.

BRAGA, Juliana Cristina. Objetos de Aprendizagem: Volume 2 - metodologia de desenvolvimento. Santo André: Editora da UFABC, 2015. ISBN 9788568576045.

CARVALHO, Ana Amélia Amorim; SIMÕES, Alcino; SILVA, João Paulo. Indicadores de qualidade e de confiança de um site. In: ALVES, Maria Palmira; MACHADO, Eusébio André (orgs.). Avaliar as aprendizagens. Actas das Jornadas ADMEE. Braga: CIEd, 2005. p. 17-28.

GUIMARÃES, Gislene Margaret Avelar; ECHEVERRÍA, Agustina Rosa; MORAES, Itamar José. Modelos didáticos no discurso de professores de ciências. Investigações em Ensino de Ciências, Brasil, Porto Alegre, v. 11, n. 3, p. 303-322, 2006.

INEP. Instituto Nacional de Estudos e Pesquisas Educacionais Anísio Teixeira. 2018. Disponível em: <http://www.inep.gov.br/>. Acesso em: jun. 2018.

MAGOGA, Thiago Flores; MUENCHEN, Cristiane. A abordagem temática na educação em ciências: a caracterização de um estilo de pensamento. Alexandria: Revista de Educação em Ciência e Tecnologia, v. 11, n. 2, p. 131-157, 2018.

MAYER, Richard E. Research-based principles for the design of instructional messages: The case of multimedia explanations. Document design, John Benjamins, v. 1, n. 1, p. 7-19, 1999.

MAYER, Richard E. Teoria cognitiva da aprendizagem multimédia. In: MIRANDA, Guilhermina Lobato (ed.). Ensino online e aprendizagem multimédia. Lisboa: Relógio D’Água, 2009. p. 207-237.

MORENO, Roxana; MAYER, Richard E. Cognitive principles of multimedia learning: The role of modality and contiguity. Journal of educational psychology, American Psychological Association, v. 91, n. 2, p. 358, 1999.

NIELSEN, Jakob. Projetando websites. [S.l.]: Gulf Professional Publishing, 2000. 
PIMENTA, Selma Garrido. Pesquisa-ação crítico-colaborativa: construindo seu significado a partir de experiências com a formação docente. Educação e pesquisa, SciELO Brasil, v. 31, n. 3, p. 521-539, 2005.

REBELATTO, Durlei Maria Bernardon; TEDESCO, Anderson Luiz. Gestão da escola e construção da qualidade na educação: Uma reflexão sobre condições e desafios de gestores escolares da mesorregião oeste catarinense. In: XI Congresso Nacional de educação. Curitiba: [s.n.], 2013. Disponível em: <http://educere.bruc.com.br/CD2013/pdf/8325_4498.pdf>. Acesso em: fev. 2019.

SILVEIRA, Fernando Lang da; BARBOSA, Marcia Cristina Bernardes; SILVA, Roberto da. Exame nacional do ensino médio (enem): uma análise crítica. Revista Brasileira de Ensino de Física, SciELO Brasil, v. 37, n. 1, p. 1101-1, 1101-5, 2015.

TAROUCO, Liane Margarida Rockenbach; FABRE, Marie-Christine J. M.; TAMUSIUNAS, Fabricio. Reusabilidade de objetos educacionais. RENOTE - Revista Novas Tecnologias na Educação: II Ciclo de Palestras sobre Novas Tecnologias na Educação, Porto Alegre, RS, v. 1, n. 1, 2003. 


\section{APÊNDICE}

Questão usada como exemplo para gráfico de barras acumuladas

\section{Enem 2013 - Questão 73 - Ciências da Natureza}

Uma indústria está escolhendo uma linhagem de microalgas que otimize a secreção de polimeros comestiveis, os quais são obtidos do meio de cultura de crescimento. Na figura podem ser observadas as proporçóes de algumas organelas presentes no citoplasma de cada linhagem.

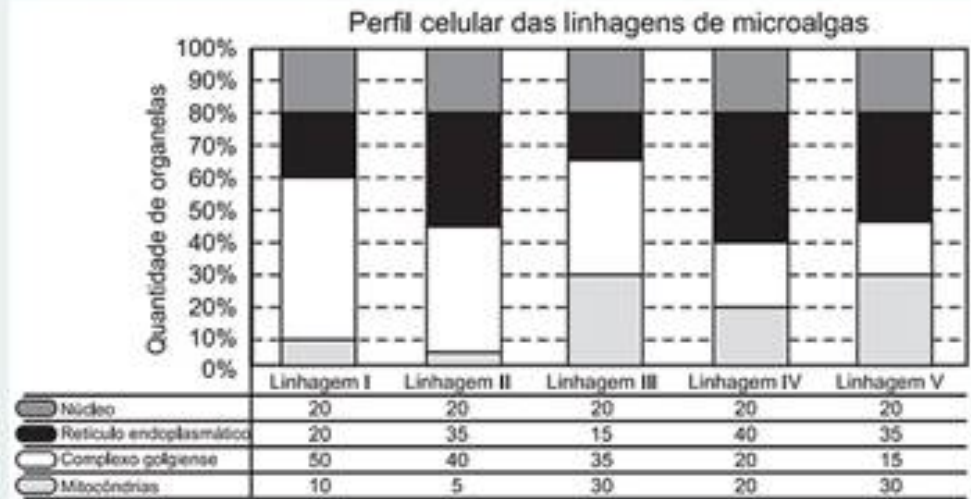

Qual é a melhor linhagem para se conseguir maior rendimento de polimeros secretados no meio de cultura?

A) 1

B) 11

C) III

D) IV

E) V

Caminhos a serem seguidos para a resolução da questão usando a técnica "Ação da roda" 


\section{Resolução da Questão Usando o Método da Roda}

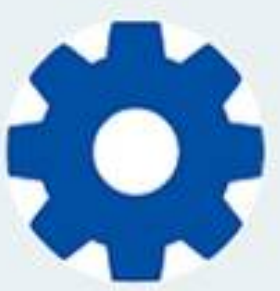

\section{IDENTIFICAÇÃO DO(S) PROBLEMA(S):}

Qual é a melhor linhagem para se conseguir maior rendimento de polímeros secretados no meio de cultura?

\section{COLETA DE INFORMAÇÖES:}

Diferentes linhagens de algas estão sendo escolhidas em função da secreção de um polímero comestivel no meio de cultura. Diferentes organelas estão presentes em diferentes proporções no citoplasma de cada linhagem.

\section{IDENTIFICAÇÃO DAS OPÇÕES:}

Na linhagem I a organela mais abundante é o Complexo Golgiense (50\%), na linhagem II a organela mais abundante é o Complexo Colgiense (40\%), na linhagem III a organela mais abundante é o Complexo Colgiense (35\%), na linhagem IV a organela mais abundante é o Retículo endoplasmático (40\%) já na linhagem $V$ a organela mais abundante é o Retículo endoplasmático (35\%).

\section{ESCOLHA DAS OPÇÖES:}

A melhor linhagem de alga é aquela que possuir mais de um determinado componente celular responsável pela maior secreção do polímero no meio de cultura. Diferentes organelas celulares apresentam diferentes funçőes.

\section{TESTES DAS SOLUÇÕES:}

Dentre as organelas citadas aquela que é responsável pela secreção de conteúdo celular é o Complexo Golgiense, portanto a linhagem com maior rendimento de polímero secretado será aquela com maior quantidade dessa organela na cếlula. A natureza química da secreção não foi citada.

\section{AVALIAÇĀO DAS SOLUÇŌES:}

Alternativa "A", pois mostra que a linhagem I é a linhagem com maior porcentagem de Complexo golgiense que é responsável pela secreção de materiais da célula. 